\title{
Evaluation of a partial retinal surface tear by optical coherence tomography
}

This article was published in the following Dove Press journal:

Clinical Ophthalmology

3I May 20II

Number of times this article has been viewed

\section{Kenji Kawazoe' \\ Hisato Ohno' \\ Kenji Inoue' \\ Yasuo Yanagi $^{2}$}

'Inouye Eye Hospital, 4-3 KandaSurugadai, Chiyoda-ku, Tokyo, Japan; 2Department of Ophthalmology, University of Tokyo School of Medicine, 7-3-I Hongo Bunkyo-ku, Tokyo, Japan
Correspondence: Hisato Ohno Inouye Eye Hospital, 4-3 Kanda-Surugadai, Chiyoda-ku, Tokyo, I0I-0062, Japan Tel +8I 33295091 I

$\mathrm{Fax}+81332930917$

Email oono-h@inouye-eye.or.jp
Abstract: Differential diagnosis of retinal hemorrhage and partial tear of the retinal surface may be difficult in some cases. A 62-year-old woman was mistakenly followed-up for small retinal hemorrhages for more than 1 year. Blocked fluorescence specific to retinal hemorrhage was not observed by fluorescein angiography (FAG). Optical coherence tomography (OCT) clearly showed defects of the retinal surface indicating partial tears of the surface at the vitreoretinal juncture and not hemorrhage. OCT is a useful and noninvasive device for the differential diagnosis of retinal hemorrhage and partial tear of the retinal surface.

Keywords: OCT, differential diagnosis, retinal surface defect,vitreoretinal juncture over retinal vessels

\section{Introduction}

Fluorescein angiography (FAG) is usually performed to evaluate retinal hemorrhage of unknown cause. In contrast, optical coherence tomography (OCT) enables precise evaluation of the retinal structure in a noninvasive manner. For retinal hemorrhage, OCT is also useful for observing a cross-section of the retina affected by hemorrhage.

We herein report a case of partial tears of the retinal surface that was mistakenly followed-up as small retinal hemorrhages until OCT clearly showed the defects of the retinal surface.

\section{Case report}

A 62-year-old woman was referred to our hospital on suspicion of retinal hemorrhage involving the retinal vessels in her left eye (Figure 1). At her first visit, visual acuity was 20/20 and as she did not have other symptoms she was to be followed-up. As the finding of her fundus had not changed 1 year later, FAG and OCT were performed to examine the cause of retinal hemorrhage. Blocked fluorescence specific to retinal hemorrhage was not observed by FAG (Figure 2). Partial defects of the retinal inner layer were however shown by OCT (Figure 3). From these results, we diagnosed this case as partial tears of the retinal surface at the vitreoretinal juncture and not hemorrhage.

\section{Discussion}

Differential diagnosis of retinal hemorrhage and partial tear of the retinal surface may be difficult in some cases, because both lesions have similar retinal colors and configurations. A case like the one we present here is probably overlooked without 


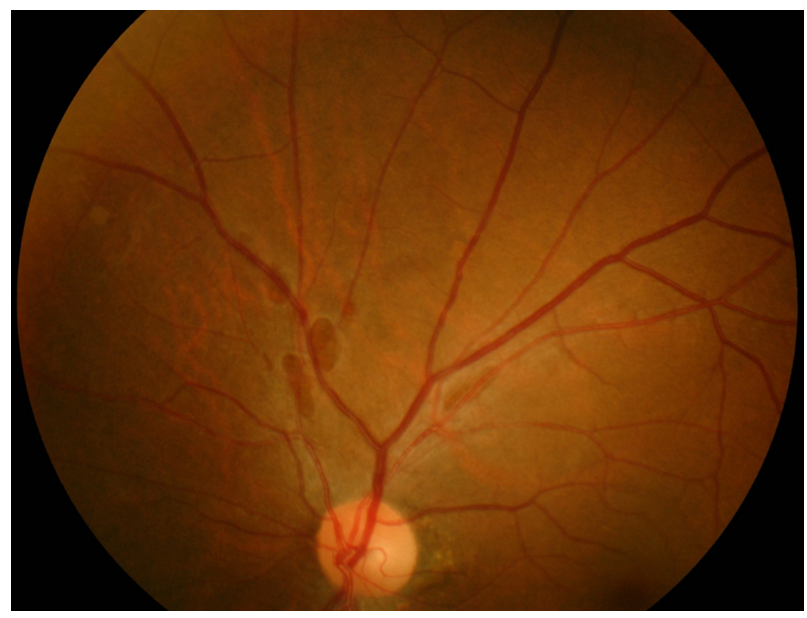

Figure I Several spots similar to retinal hemorrhage were seen along with the vessels superior to the disc.

further examinations in routine work. OCT is a useful and noninvasive device for the differential diagnosis of retinal hemorrhage and partial tear of the retinal surface. OCT shows an image of partial tear of the retinal surface as a defect of the inner layer of the retina. The image is quite different from that of retinal hemorrhage.

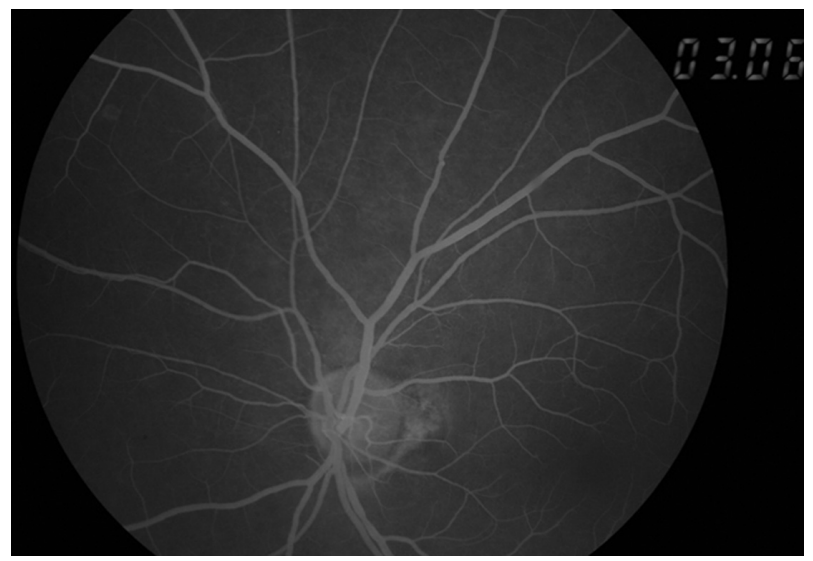

Figure 2 Fluorescein blockage specific to retinal hemorrhage was not shown in fluorescein angiography.

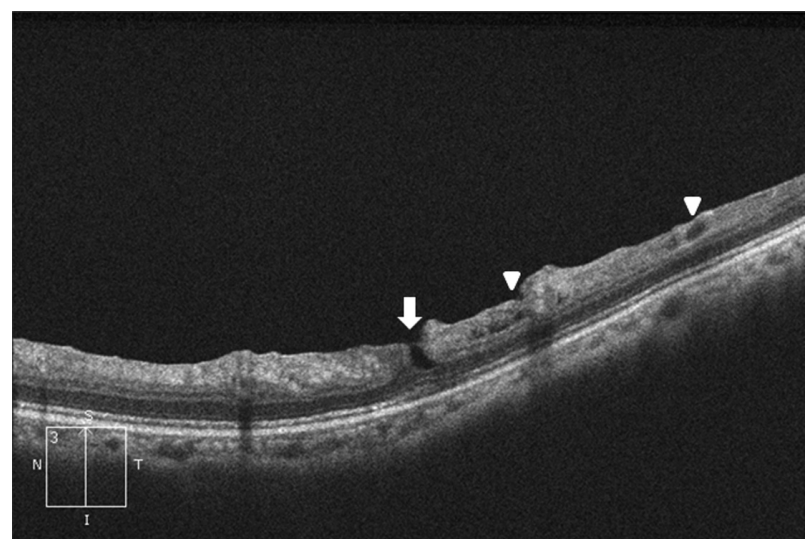

Figure 3 Optical coherence tomography reveals the defects of the inner layer of the retina equivalent to the partial tear (arrow) and small surface break (arrowhead).

Foos RY emphasized the causative role of vitreous traction with partial tears of the retinal surface being caused by posterior vitreous detachment, and proposed three events that predispose to or cause small surface breaks: developmental thinning of the inner limiting lamina; subsurface retinal degeneration; and transmigrating macrophages. When small surface breaks become complicated by vitreous incarceration or by simple epiretinal membrane formation, direct posterior vitreous detachment may peel portions of the superficial retina, and the resulting large surface breaks may in turn provoke complex proliferative lesions of the vitreoretinal juncture. $^{1}$

In our case, OCT clearly showed the defect of the inner layer of the retina and small surface break. Regular follow-up of the retina is needed to detect further complications.

\section{Disclosure}

No conflicts of interest were declared in relation to this paper.

\section{Reference}

1. Foos RY. Vitreoretinal juncture over the retinal vessels. GraefesArchiv Ophthalmologie. 1977;204:223-234.
Clinical Ophthalmology

\section{Publish your work in this journal}

Clinical Ophthalmology is an international, peer-reviewed journal covering all subspecialties within ophthalmology. Key topics include: Optometry; Visual science; Pharmacology and drug therapy in eye diseases; Basic Sciences; Primary and Secondary eye care; Patient Safety and Quality of Care Improvements. This journal is indexed on
PubMed Central and CAS, and is the official journal of The Society of Clinical Ophthalmology (SCO). The manuscript management system is completely online and includes a very quick and fair peer-review system, which is all easy to use. Visit http://www.dovepress.com/ testimonials.php to read real quotes from published authors. 